\title{
用于全球变化研究的中国植物功能型划分
}

\author{
翁恩生 周广胜 * \\ (中国科学院植物研究所植被数量生态学重点实验室, 北京 100093)
}

摘 要 植物功能型( Plant functional types, PFTs) 作为沟通植物的结构和功能与生态系统属性的桥梁, 随着全球变 化与植被的关系研究的深入而受到广泛重视。植物功能型的划分依赖于研究的背景、尺度和要解决的问题。为了 区域尺度全球变化研究的需要, 该文提出了一个基于植物关键特征的植物功能型划分方法。该方法首先选择了 6 项植物特征, 包括 3 项冠层特征: 木本-草本、常绿-落叶和针叶-阔叶, 以及 3 项生理特征: 光合途径 $\left(\mathrm{C}_{3} / \mathrm{C}_{4}\right)$ 、植物的 水分需求和热量需求, 作为划分植物功能型的关键特征; 然后, 先根据植物冠层特征划分得到 5 个基本类型, 再根 据水分和热量条件进行详细划分, 得到 29 种备选类型; 需要时, 再根据研究目的从这 29 种备选类型中选择所需类 型。根据这个方法, 在充分考虑了我国季风气候条件下特有的水热配置和高海拔环境对植物的形态和功能特征影 响的基础上, 从备选类型中选择了一套适合中国气候和植被特征的植物功能型体系。这套体系包括 18 类植物功 能型, 其中含 7 类 “树”功能型、 6 类 “灌木’功能型和 5 类 “草”功能型, 另根据需要设置 2 类 “裸地”功能型。并且根 据植物的生理生态特征和中国植被的地理分布确定了用于限制植物功能型分布的气候因子, 这些气候因子包括绝 对最低温度、最暖月平均温度、有效积温、年最热月平均温和最冷月平均温之差、湿润指数、年均降水量。应用表 明, 这套植物功能型可用于模拟我国植被在当前气候条件下的分布。该研究为发展适于我国的植被模型和区域气 候模型、评估全球变化对我国植被的影响及植被变化对气候的反馈作用提供依据与参数。

关键词 植物功能型 关键植物特征 气候-植被相互作用 中国植被 全球变化

\section{DEFINING PLANT FUNCTIONAL TYPES IN CHINA FOR GLOBAL CHANGE STUDIES}

\author{
WENG En-Sheng and ZHOU Guang-Sheng ${ }^{*}$ \\ ( Laboratory of Quantitative Vegetation Ecology, Institute of Botany, Chinese Academy of Sciences, Beijing 100093, China)
}

\begin{abstract}
Plant functional types (PFTs) bridge the gap between plant physiology and ecosystem processes, providing a powerful tool for studies on global change, vegetation dynamics and vegetation-atmosphere processes. In this paper, a two-stepped hierarchical PFT classification system was proposed based on six key plant attributes. Three of six key attributes were related to plant canopy structure, including permanence of aboveground live biomass ( woody vs. herbaceous), leaf longevity (evergreen vs. deciduous) and leaf structure (broad-leaved vs. needle-leaved). The other three attributes were related to plant physiological characteristics, including photosynthetic pathway (i.e. $\mathrm{C}_{3}$ vs. $\mathrm{C}_{4}$ grasses), drought resistance and temperature tolerance (e.g. warm evergreen, cool conifer). In the first step of the analysis, five basic plant types were derived based on canopy attributes. In the second step, these five basic plant types were sub-divided into 29 types according to their photosynthetic pathways, drought resistance and temperature tolerance. We tested this PFT classification system by simulating the distribution of vegetation in China. A sub-set of 18 plant types was selected from the 29 PFTs that were characteristic of the vegetation in China, especially in relation to the water balance and energy budget as affected by the monsoon climate and the Tibetan Plateau. This set of PFTs contained 7 trees, 6 shrubs and 5 grasses. Two types of bare ground were added for the simulation. Six climatic variables were selected to be used as the distributional constraint of each PFT, which included absolute minimum temperature $\left(T_{\min }\right)$, mean temperature of the warmest month $\left(T_{\mathrm{w}}\right)$, growing-day degrees $(G D D \mathrm{~s})$, annual range of monthly mean temperature $(D T Y)$, moisture index (annual precipitation-annual potential evapotranspiration, $M I)$, annual precipitation $(P)$. The values of these climatic variables were determined based on the geographical distribution of each plant functional type. Using BIOME1, the distribution of the PFTs across China was then modeled. The simulated map of China's vegetation was in close agreement with the ac-
\end{abstract}


tual vegetation map, indicating that this set of PFTs was capable of simulating the geographical distribution of vegetation in China. This study provides a basis for future studies on climate-vegetation interactions and for developing regional dynamic vegetation models and regional climate models for China.

Key words Plant functional types, Key plant traits, Vegetation-atmosphere interactions, Chinese Vegetation, Global change

以“气候变暖”为标志的全球变化及其对人类生 存环境的严重影响已经引起了科学家、各国政府与 社会各界的严重关注。据估计, 到本世纪末地球大 气中 $\mathrm{CO}_{2}$ 浓度将增至将近 $900 \mathrm{ppm}($ IPCC, 2001), 由 此引起的全球不同区域的温度和降水的变化必将对 全球陆地生态系统产生严重影响。而植被的变化又 将通过影响植被与大气之间的物质(如水和 $\mathrm{CO}_{2}$ 等) 和能量(如太阳辐射、动量和热量等) 交换来影响气 候, 从而加剧全球变化的影响 (Gallimore \& Kutzbach, 1996; Foley et al., 1998; IPCC, 2001)。正因为如 此, 发展监测与预测陆地生态系统变化的模式, 找出 应对全球变化不良影响的策略、方法和途径, 以达到 预警、调节和最大限度地减小全球变化不良影响的 效果, 保证地球成为一个适宜于人类生存与可持续 发展的生命支持系统成为当前迫切需要解决的生存 问题, 也是当前全球变化研究的核心。为此, 国际地 圈-生物圈计划 ( International geosphere-biosphere program, IGBP) 将“预测气候、大气成分和土地利用变 化对陆地生态系统的影响, 以及确定这些影响如何 反馈于大气和物理气候系统” 作为其核心项目 “全球 变化与陆地生态系统 (Global change and terrestrial ecosystem, GCTE)”的重要研究目标。

目前, 已经建立了许多局地尺度模型和区域尺 度模型, 用以评估全球变化对陆地生态系统的潜在 影响 (如 JABOWA, Botkin et al., 1972; FORECE, Kienast, 1987; FOREST-BGC, Running \& Gower, 1991; NEWCOP, 延晓冬和赵士洞, 1996)。关于气 候、大气成分和土地利用变化对陆地生态系统的影 响如何反馈于全球气候系统是一个全球性问题, 需 要建立全球尺度模型, 而建立全球尺度模型的关键 在于如何定量地描述组成陆地生态系统的植被的功 能与结构的多样性 (Cramer, 1997)。对于地球上每 一生态系统建立模型是不现实的, 而且这些模型亦 不能代表这些生态系统中的每一个植物种 (Smith et $a l$, 1997)。因此, 在模型中采用少量的功能型来减 少描述植物的复杂性是发展全球尺度植被模型的关 键, 也是 IGBP 核心项目 GCTE 的研究核心 (Smith et al., 1997)。

植物功能型( Plant functional types, PFTs)指对环
境条件具有相似响应机理的一组植物种, 代表着陆 地主要生态系统中优势植物种类的组合 (Gitay \& Noble, 1997)。植物功能型不仅是减少生态系统复 杂性的有效工具, 而且可将植物的生理生态过程、生 物物理特征和物候变化引入动态植被模型中 (Smith, 1997), 从而有助于从机理上描述植被的动 态。目前, 植物功能型已被广泛用于生物地理模型 (Prentice et al., 1992; Haxeltine \& Prentice, 1996)、 生物地球化学模型 (Haxeltine et al., 1996)、陆面过 程模型 (Sellers et al., 1986; Bonan, 1996; Bonan et $a l$, 2002) 和全球动态植被模型 (如 Hybrid3, Friend et al., 1997; IBIS, Feoly et al., 1996; LPJ-DGVM, Sitch et al., 2003; NCAR-DGVM, Bonan et al., 2003)。

我国位于地球环境变化速率最大的东亚季风 区, 其环境具有空间上的复杂性、时间上的易变性, 对外界变化的响应和承受力具有敏感和脆弱的特 点。同时, 我国是具有 5000 余年历史的文明古国, 区域开发同样历史源远流长, 当前又处于经济高速 发展、人口压力剧增的时期, 以气候变暖为特征的全 球变化必将对我国陆地生态系统产生严重影响。研 究表明, 在温度增加 $2{ }^{\circ} \mathrm{C}$ 至 $4{ }^{\circ} \mathrm{C}$, 降水增加 $20 \%$ 时, 我国各植被带均有所北移, 特别是寒温针叶林地带 可能北移出中国, 西部草原和青藏高原地带沙漠化 趋势加强(张新时, 1993; 周广胜和张新时, 1996; 赵茂盛等, 2002)。因此, 如何准确地评估我国陆地 生态系统对于全球变化的响应, 以找出科学的对策, 最大限度地减小全球变化的不良影响是我国全球变 化研究者面临的严峻挑战。而建立一套适合中国气 候和植被特征的植物功能型体系是发展我国区域植 被动态模型, 从而正确预测我国植被的变化和对气 候的反馈的关键。

一些学者已经对中国植物功能型开展了初步的 研究, 如: 沿某一环境梯度开展植物功能型的划分研 究 (Tang, 1999; Ni, 2002); 根据植物外貌、叶片特征 和农作物光合途径及熟制将中国植被划分为 38 种 植物功能型 (倪健, 2001); 或根据欧亚大陆土地利 用和覆盖模拟研究的需要, 从 Box 体系 (Box, 1981) 中直接选取植物功能型 (van Minnen et al., 1996)。 
特别是, 倪健 (2001) 关于中国植物功能型的划分基 本反映了中国植被的特征和分布格局, 但该分类体 系中的植物功能型基本上是我国植被类型的缩影, 并且对每种类型缺乏明确的定义, 因此难以给出每 种功能型地理分布的环境限制参数和植物功能型在 气候-植被相互作用中的功能参数, 从而限制了它在 区域动态植被模拟中的应用。

本文针对我国独特的季风气候和青藏高原特 征, 以中国各植被类型中的优势植物种类为对象, 开 展中国植物功能型研究, 以期提出一套适于中国气 候的植物功能型划分方法和气候指标体系, 为发展 适于我国的植被模型和区域气候模型、评估全球变 化对我国植被的影响及植被变化对气候的反馈作用 提供依据与参数。

\section{1 植物功能型的划分原理与方法}

\section{1 用于植物功能型划分的关键植物特征}

植物是通过尽最大可能改变自己的形态和生理 特征以适应环境, 从而获得生存机会的生物体。在 长期的进化过程中, 各种植物演化形成了多种多样 的结构和功能特征, 这些特征对植物的生命活动和 生存是不可或缺的。在大的空间尺度上, 其中的一 些特征在植被-大气间的相互作用中扮演着重要的 角色, 特别是植物的冠层特征, 它直接参与了植被大气间的相互作用 (Bonan, 1995; Running et al., 1995)。无论对地球系统还是对于植物本身, 光合作 用都是最具意义的一项生理活动, 而叶片是绝大多 数植物进行光合作用的场所。因此, 植物形成了以 叶片为核心的冠层结构。植物冠层的生态外貌特征 深受气候状况影响, 如植物体的大小、有效叶面积、 叶片结构和叶片质地以及植物的季节变化等, 具有 很强的气候可塑性, 能敏锐地反映气候的变化 (Box, 1981, 1995)。植物的水分和能量需求主要通 过这些特征进行调节, 如改变植物表面面积(主要是 叶面积)、植物表面(气孔)的气体交换以及植物体的 大小。所以, 应用于大尺度研究的植物功能型划分 的标准也逐渐集中在以叶片特征为核心的植物冠层 特征上。

通常用于大尺度植物功能型划分的一些关键特 征有: 木本-草本、常绿-落叶、阔叶-针叶, 以及生理特 征: 抗寒性 (如暖常绿、凉针叶) 、光合途径 (如 $\mathrm{C}_{3}$ 草$\mathrm{C}_{4}$ 草)(Kittel et al., 2000; Bonan et al., 2002)。这 些特征在很大程度上决定着植物的生物物理和生理 特征, 同时对植物的生存和生理活动, 特别是植物对
气候变化的反应, 起着至关重要的作用。综合考虑 植物的形态和生理特征, 以及气候变量对植物特征 的限制是划分植物功能型的有效方法。这些特征不 仅限制着植物形态和生理特征本身的变化幅度, 如 气孔导度、光合作用和光合产物分配, 同时也深刻影 响着植物的生物物理和生物地球化学特征, 如植物大气间的能量、水分和 $\mathrm{CO}_{2}$ 交换, 以及陆地表面的粗 糙度和反射率等, 进而构成了以植被为主的陆地表 面的生物物理特征和生物地球化学特征, 从而影响 着植被-大气的相互作用。

木本-草本 植物体的外貌是植物的形态特征 中最重要的一个, 它对植物的适应有着多方面的影 响 (Box, 1981)。植物的外貌非常复杂, 为了简化, 我们仅区分木本和草本。草本植物和木本植物的生 存策略有着根本的不同。通常, 木本植物比非木本 植物有着更长的寿命, 同时也需要更多的资源去维 持本身的生存 (Ehrlen \& Lehtila, 2002)。只有木本植 物才可能形成高大的植株, 从而可以配置更多的叶 片, 获取更多的光照。木本植物体的形态复杂, 灌木 和乔木是两个重要的结构类型。一般认为, 木本植 物的基本大小和高度由水分控制 (Friend, 1993; Becker et al. , 2000)。木本植物有着全年存活的地 上部分和稳定的植株结构, 对正常的气候波动不敏 感; 而草本植物的地上部分冬季或旱季通常死去, 并 且对气候的年际变化比较敏锐。这些特点在季节气 候变化和碳平衡模拟方面有重要的作用。木本和草 本植物影响着地表的粗糙度, 是气候模型中能量和 动量交换的重要参数 (Running et al., 1995)。

常绿-落叶 二者最大的不同在于它们的光合 特征。落叶植物的叶片含氮量高, 光合速率很高, 叶 片在短期内能合成大量的同化产物, 但寿命短; 而常 绿植物叶片的含氮量较低, 光合速率也小, 但光合维 持时间长 (Reich et al., 1992; Eamus，1999)。常绿 植物能够在气候合适时迅速恢复光合能力, 而落叶 植物能够通过落叶抵御周期性的干旱和寒冷 (Box, 1981)。对热带地区的常绿和落叶树种的研究表明, 成熟的常绿树木在干季光合作用只下降 $15 \%$ $20 \%$, 而落叶树种则下降 100\%（Eamus \& Cole, 1997; Franco，1998）。植物的常绿和落叶属性也影 响着植物茎干的输水能力。热带常绿植物茎的每叶 导度 (Leaf-specific conductivity, $L S C$; 茎向叶片供水 能力的指标)通常比落叶树种大, 这意味着同样的蒸 腾量, 常绿树种需要的土壤-叶片水压差较小 ( Eamus, 1999)。叶片的季节变化在碳循环动态中是一 
个非常重要的特征, 同时它也影响着地表反射率和 能量传输的季节变化。从植物的常绿和落叶特征, 可以推导不同功能型的冠层导度和最大光合速率, 它们是动态植被模型中的重要参数。

阔叶-针叶 针叶植物的光合效率(单位叶片生 物量的光合产物)通常小于阔叶植物; 针叶植物一般 生长在寒冷的区域, 它可以在耐寒的情况下, 维持一 个可以维持植物生存的稍低的光合速率。尽管在温 暖的区域也存在一些种类, 但一般只存在于次生林 地上,会随着植被演替而被阔叶植物取代 ( Becker, 2000）。在幼苗阶段, 针叶树种的最大生长速度通常 小于阔叶植物 (Enright et al., 1993; Read, 1995; Cornelissen et al., 1996)。这会导致在生长条件好、 竞争片层发育迅速的地方, 针叶植物幼苗被阔叶植 物取代 (Lusk \& Matus, 2000)。古生态学家注意到, 针叶植物起源时 $\mathrm{CO}_{2}$ 浓度较高, 所以它的气孔密度 较低。在地质历史时期, 大气 $\mathrm{CO}_{2}$ 浓度有过很大波 动, 但针叶植物的气孔密度变化很小, 与 $\mathrm{CO}_{2}$ 波动水 平不相适应 (Beerling \& Woodward, 1996)。它们的气 体交换至今仍然被其保守的气孔特征所限制。而后 来进化产生的木兰纲植物却因具有高密度和可有效 调节的气孔而可以更好的适应后来较低的 $\mathrm{CO}_{2}$ 浓度 (Robinson, 1994)。阔叶和针叶植物的能量和水分 传输以及其它生态生理特征有很大的不同, 如光合 速率, 冠层导度有很大差异 (Christopher et al., 2003 ), 它们影响到生物地球化学模型中许多重要参 数的确定 (Running et al., 1995)。

光合途径 陆地植物中发现有 3 种光合途径, 它们是: $C_{3} 、 C_{4}$ 和景天酸代谢途径 (Crassulacean acid metabolism, CAM）。 $\mathrm{C}_{3}$ 途径是一个古老的碳同化途 径, 存在于所有的光合植物中, 它的第一步反应是将 $\mathrm{CO}_{2}$ 与异戊二磷酸核酮糖 ( RuBP) 结合, 形成 2 个三 羧酸, 开始葡萄糖的合成过程, 并储存能量。 $\mathrm{C}_{4}$ 途 径主要存在于更为进化的植物类群中, 特别是在单 子叶植物中非常普遍。它先将进入细胞的 $\mathrm{CO}_{2}$ 合成 一个四羧酸, 然后运输到维管束鞘细胞中, 进行三羧 酸循环, 合成葡萄糖。CAM 途径存在于异常干旱地 区的许多附生和肉质植物中, 它在白天将 $\mathrm{CO}_{2}$ 合成 景天酸, 晚上再进行还原性化合物 (糖) 的合成。因 为 CAM 植物的分布十分有限, 所以它们在全球碳循 环中的作用微乎其微 (James \& Cerling, 2002)。

$\mathrm{C}_{3}$ 途径和 $\mathrm{C}_{4}$ 途径因关键酶和反应过程的不同 而导致对环境反映的巨大差异 ( James \& Cerling, 2002）。 $\mathrm{C}_{4}$ 植物更适宜于高温和干旱的环境, 并且在
$\mathrm{CO}_{2}$ 浓度偏低的情况下仍然能维持相当的光合速 率。而在这种环境下, $\mathrm{C}_{3}$ 植物的光呼吸很强烈, 严 重限制了它的同化反应。在气温较低的情况下, 随 着光呼吸速度的降低, $\mathrm{C}_{3}$ 途径光利用效率高的特点 又表现出来。 $\mathrm{C}_{3}$ 和 $\mathrm{C}_{4}$ 植物对温度变化和大气 $\mathrm{CO}_{2}$ 浓度变化的响应有着很大的不同。从全球变化的观 点看, 光合途径的类型影响到了生态系统碳同化的 速度和动物所能得到的食物数量以及释放到大气中 的 $\mathrm{CO}_{2}$ 的同位素组成。

植物的温度和热量需求 温度是限制植物分布 的重要因素。热带植物通常不能忍受零上低温的侵 袭( Woodward, 1987), 而北方树种的低温忍受能力似 乎是无限的, 限制它们向背分布的因素是积温 (Heat sum, Growing degree-days, GDD) (Prentice et al., 1992)。一些温带植物为了启动生殖生长, 必需一定 长度和强度的低温 (春化作用)。

植物的水分需求 水分对植物形态的限制是决 定性的。陆生植物经常受到干旱胁迫, 抗旱特性是 植物重要的特征。植物的抗旱性与它的形态紧密相 连, 为了尽可能多的获取光照, 植物总是需要大的冠 层, 但是, 这样就扩大了蒸腾面积, 增加了水分消耗 (Woodward, 1987)。抗旱结构 (如角质层)的产生, 使 植物更具抗旱能力, 但是, 这样不仅加大了在叶片上 的投入 (光合产物分配), 也使气孔导度降低, 限制了 $\mathrm{CO}_{2}$ 进入气孔的速度。通常认为, 水分供应影响了 植物的外貌, 如树木、灌木和草本的区分, 因为维持 一个大的冠层需要较多的水分消耗 (Woodward, 1987; Woodward \& McKee, 1991)。

植物通过形态、物候和生理调整来适应自然界 的温度和水分变化, 如落叶往往是和干旱或寒冷季 节的到来相伴的, 是植物耐旱或耐寒的一种适应方 式; 针叶植物通常比阔叶植物耐寒; $\mathrm{C}_{4}$ 草类通常出 现在炎热的干旱地区等等。因此,这 6 类特征是密 切关联的。

\section{2 植物功能型的划分方法}

植物功能型的划分必须根据研究背景和需要而 定（Cramer et al., 1999）。考虑到这套植物功能型将 用于植被分布对气候变化的反馈, 以及区域植被动 态模拟的研究需要, 我们根据前人的原理和方法

(Box, 1981; Running et al., 1995; Nemani \& Running, 1996), 提出了一个两步骤的划分方案: 首先, 根据植物冠层特征得到 5 个基本类型, 然后, 根据环 境因素 (温度、水分) 以及光合途径以进行细分, 得到 29 类备选类型; 使用时, 再根据研究需要选择所需 
的植物功能型。

\subsection{1 第一步的依据是植物冠层特征}

我们根据所选定的 3 个植物冠层特征: 地上植 物体的寿命、叶片寿命和叶片类型, 将植物分为 5 类。

首先, 根据植物体地上部分是多年生还是一年 生, 将木本和草本植物区分开来。通常, 多年生的为 木本植物, 一年生的是草本植物; 然后, 根据植物叶 片的维持时间将木本植物区分为常绿植物和落叶植 物, 草本植物只有在生长季才生有叶片; 最后, 根据 叶型(只选择阔叶和针叶 2 个特征) 将植物区分为阔 叶植物和针叶植物。这样, 得到了 5 个基本类型(图 1)。

\subsection{2 第二步的依据是植物的水分和温度条件}

首先, 根据水分条件将木本植物区分为树木、灌 木和荒漠灌木。高大乔木和灌木区分的主要特征是 高度和叶面积指数。通常认为, 植株高度由水分决 定,而叶面积指数也是反映水分状况的一个指标 （Woodward \& Mckee，1991）,所以我们选择水分指标 对乔木和灌木进行区分。然后, 再根据温度条件将 木本植物区分为热带、温带和北方 3 类。草类植物 分别根据光合途径和水分温度需求进行分类。
木本植物的划分 根据水分和温度需求组合划 分为 27 类, 其中树木 12 类, 灌木 15 类 (图 2)。

草本植物的划分 根据应用需要的不同才用 2 个划分标准: 光合途径或植物的耐寒耐旱能力, 分 别得到 2 类或 6 类草类功能型 (图 3)。

$\mathrm{a}$ 根据植物的水热需求划分一一通常应用于生 物地理模型

首先根据水分需求划分为湿生草(草原草)和旱 生草(草甸草), 然后根据温度条件区分为热带(萨王 纳)、温带(温带草原)和高寒(极地)3 类。

$\mathrm{b}$ 根据光合途径区分为 $\mathrm{C}_{3}$ 和 $\mathrm{C}_{4}$ 草一一通常应 用于生物地球化学模型和动态植被模型

$\mathrm{C}_{3} / \mathrm{C}_{4}$ 草事实上经常用温度区分, 如 Nemani 和 Running (1996) 曾用年最低温度 $-1{ }^{\circ} \mathrm{C}$ 和年最高温 度 $22{ }^{\circ} \mathrm{C}$ 作为区分 $\mathrm{C}_{3} / \mathrm{C}_{4}$ 草原的界限, 高于这两个温 度界限时, 草原类型被认为是 $\mathrm{C}_{4}$ 类型。

经过上述两个步骤的划分, 共得到了 29 类备选 类型(表 1 )。这些类型并不能囊括全部的植物种 类, 但它可以将主要的植物, 特别是那些决定着植被 类型和陆地表面生物物理和生物地球化学特征的关 键植物, 归入到这些功能类型中来，从而使得这一 整套植物功能型足以反映地表的生物地理、生物物

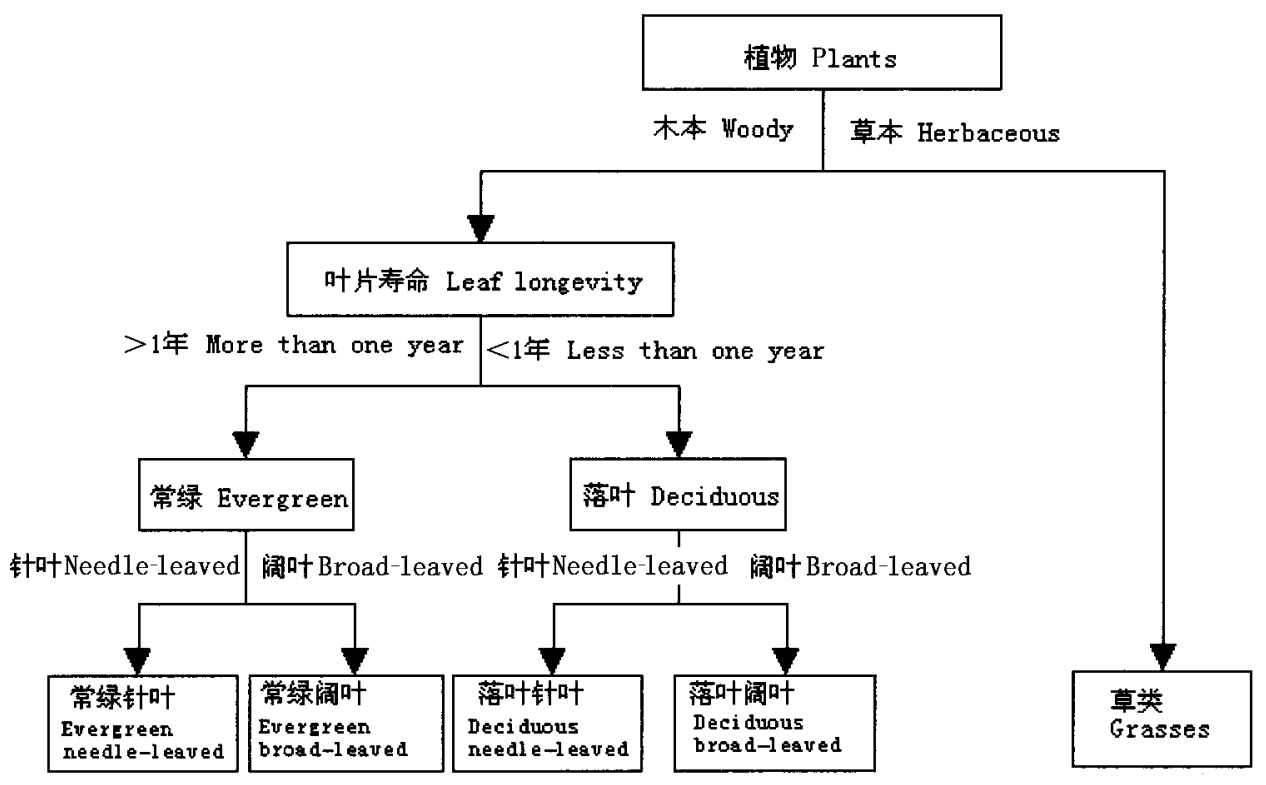

图 1 基本类型划分一一依据植物冠层特征

Fig. 1 The classification of basic types according to canopy characteristics 
水分 Water availability

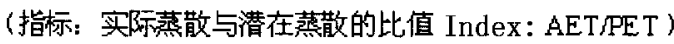

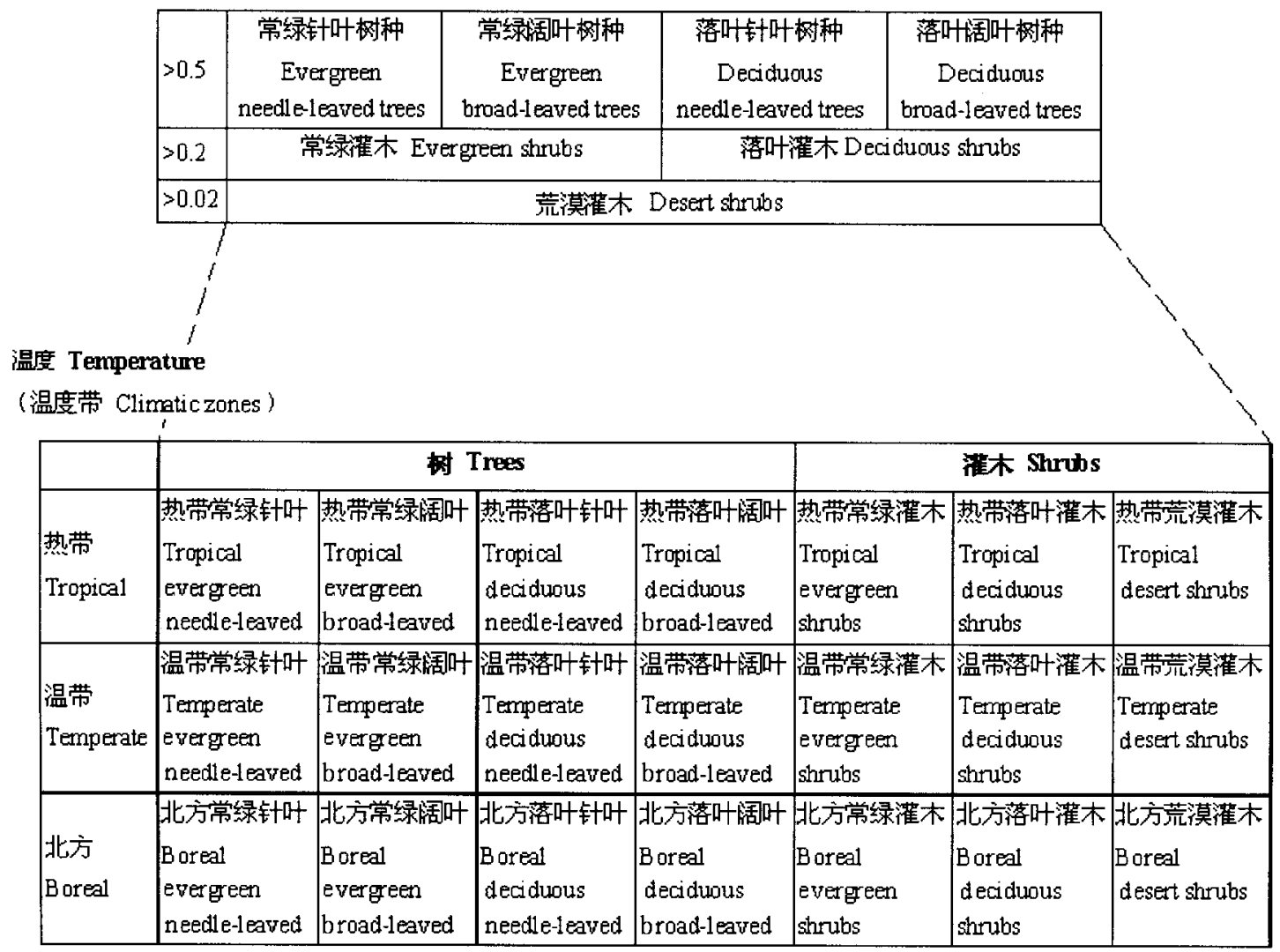

图 2 木本植物功能型划分

Fig.2 Classification of woody functional types

a

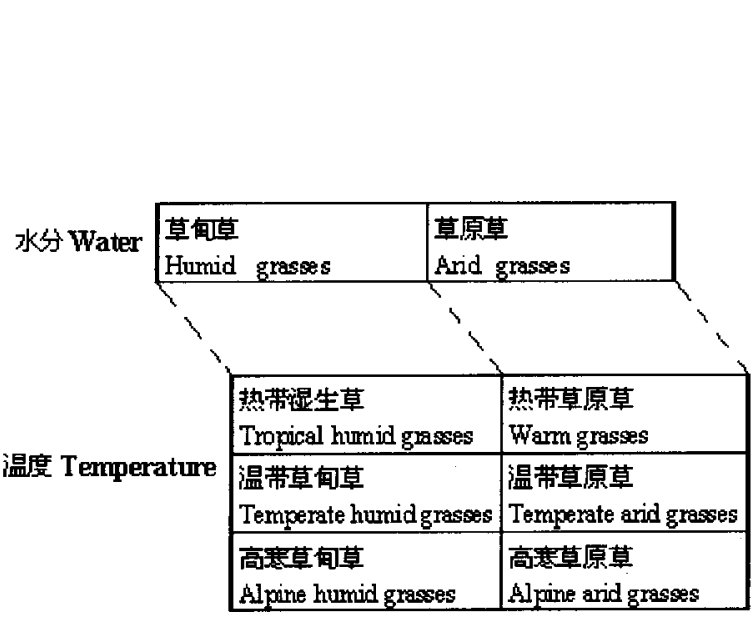

b
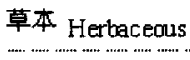

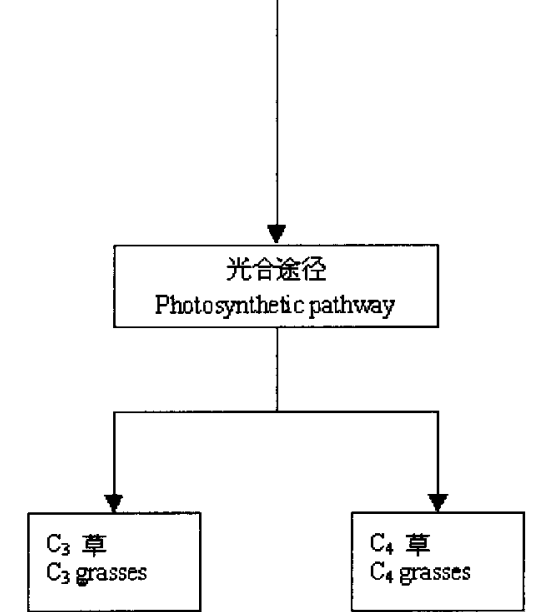

a. 依据水分和温度条件 According to conditions of moisture and temperature b. 依据光合途径 According to photosynthesis pathways 图 3 草本植物功能型划分

Fig. 3 Classification of grass functional types 
表 1 备选的植物功能型

Table 1 The PFTs for selection

\begin{tabular}{|c|c|c|c|c|}
\hline & \multicolumn{4}{|c|}{ 植物功能型 Plant functional types } \\
\hline \multirow{6}{*}{$\begin{array}{l}\text { 树 } \\
\text { Trees }\end{array}$} & 热带常绿针叶树种 & 热带常绿阔叶树种 & 热带落叶针叶树种 & 热带落叶阔叶树种 \\
\hline & Tropical evergreen coniferous & Tropical evergreen broad-leaved & Tropical deciduous coniferous & Tropical deciduous broad-leaved \\
\hline & 温带常绿针叶树种 & 温带常绿阔叶树种 & 温带落叶针叶树种 & 温带落叶阔叶树种 \\
\hline & Temperate evergreen coniferous & Temperate evergreen broad-leaved & Temperate deciduous coniferous & Temperate deciduous broad-leaved \\
\hline & 北方常绿针叶树种 & 北方常绿阔叶树种 * & 北方落叶针叶树种 & 北方落叶阔叶树种 \\
\hline & Boreal evergreen coniferous & Boreal evergreen broad-leaved & Boreal deciduous coniferous & Boreal deciduous broad-leaved \\
\hline \multirow{6}{*}{$\begin{array}{l}\text { 灌木 } \\
\text { Shrubs }\end{array}$} & 热带常绿灌木 & 热带落叶灌木 & 热带荒漠灌木 & \multirow{2}{*}{ - } \\
\hline & Tropical evergreen & Tropical deciduous & Tropical desert & \\
\hline & 温带常绿灌木 & 温带落叶灌木 & 温带荒漠灌木 & \multirow{2}{*}{-} \\
\hline & Temperate evergreen & Temperate deciduous & Temperate desert & \\
\hline & 北方-高寒常绿灌木 & 北方-高寒落叶灌木 & 高寒荒漠灌木 & \multirow{2}{*}{ - } \\
\hline & Boreal-Alpine evergreen & Boreal-Alpine evergreen & Alpine desert & \\
\hline \multirow{6}{*}{$\begin{array}{l}\text { 草 } \\
\text { Grasses }\end{array}$} & 热带湿生草 & 热带草原草 & $\mathrm{C}_{4}$ 草 & \multirow{2}{*}{-} \\
\hline & Tropical humid & Warm & $\mathrm{C}_{4}$ grasses & \\
\hline & 温带草甸草 & 温带草原草 & - & \multirow{2}{*}{ - } \\
\hline & Temperate humid & Temperate arid & & \\
\hline & 高寒草甸草 & 高寒草原草 & $\mathrm{C}_{3}$ 草 & \multirow[t]{2}{*}{ - } \\
\hline & Alpine humid & Alpine arid & $\mathrm{C}_{3}$ grasses & \\
\hline
\end{tabular}

一: 不存在相应植物的类型 The types that have no relative plant species

理和生物地球化学特征。

\section{2 应用}

根据需要选择了其中的 18 类, 包括 7 类高大乔 木 (树)、6 类灌木和 5 种草类, 作为我国实际存在的 优势植物功能型。依据 BIOME 模型 (Prentice et al., 1992) 的原理, 用这 18 类植物功能型模拟我国植被 的潜在地理分布, 由此检验这套分类体系的合理性。

\section{1 植物功能型选择}

依据我国的植被特征, 选择优势植物功能型, 如, 热带常绿针叶树种和热带常绿阔叶树种同时存 在于同一区域, 考虑到热带常绿针叶树种很少, 且多 零星分布, 如南亚松 ( Pinus latteri)、海南五针松 ( $P$. fenzeliana) 和喜马拉雅长叶松 ( $P$. roxburghii) 等, 为 此以占优势的热带常绿阔叶树种为特征来确定植物 功能类型。同样, 温带落叶针叶树种亦与温带阔叶 树种同处于同一地区, 亦以占优势的温带阔叶树种 为特征来确定植物功能类型; 北方落叶阔叶树种因 完全可以被温带落叶阔叶树种代表, 所以不选; 灌木 主要用于表现草原和荒漠等干旱区域的植物, 所以 作为林下成分的热带常绿灌木和温带常绿灌木没有 被选入; 由于我国缺乏热带荒漠类型,所以热带荒漠 灌木也没有被选入; “热带湿生草”因为不是热带森 林的优势植物而没有入选; $\mathrm{C}_{3}$ 和 $\mathrm{C}_{4}$ 草因为它们与 根据水分和温度划分得到的草类功能型二者只能选
其一, 所以也没被选入。这样共选出 18 类功能型 （表 2）。其中,一些“北方”类型被设置为“高寒”类 型, 用于代表青藏高原及其它高海拔区域的植物类 型。

2.2 植物功能型代表种类选择和分布范围的确定

首先, 根据植物功能型划分的 6 项关键特征, 结 合《中国植被》记载的各个植被类型的优势植物种和 相关植物区系资料的植物特征描述, 为每个植物功 能型选择代表性植物种类; 然后, 在确认该优势种的 植物功能型归属后, 基于该优势种的地理分布, 结合 《中国植被图》绘制出该植物功能类型的地理分布 图。绘制植物功能型分布图的主要目的在于计算植 物功能型的气候限制参数值。

\section{3 气候参数选择和参数值的确定}

有 3 类气候因子决定着植物的分布 (Woodward, 1987), 它们是: 1)植物能够忍受的最低温度;2)完成生 活史所需的生长季长度和热量供应;3)用于植物冠层 形成和维持的水分供应。通常认为, 水分供应则决定 植物的外貌 (如乔木、灌木、草本以及常绿和落叶等), 绝对低温限制着树木的分布范围(Fang et al., 2002)。 这个观点也被用于指导气候变量的选择。

根据气候与植物分布关系的研究 (Woodward, 1987; Box, 1981; Prentice et al., 1992; Box, 1995) 和我国气候-植被关系的相关研究 (Fang \& Yoda, 1989，1990; 方精云，2001; 张新时，1993; 杨正宇 
表 2 用于模拟中国植被分布的植物功能型

Table 2 PFTs selected for simulating Chinese vegetation distribution

\begin{tabular}{|c|c|c|c|c|}
\hline & \multicolumn{4}{|c|}{ 植物功能型 Plant functional types } \\
\hline \multirow{6}{*}{$\begin{array}{l}\text { 树 } \\
\text { Trees }\end{array}$} & $x$ & 热带常绿阔叶树种1） & $x$ & 热带落叶阔叶树种2) \\
\hline & & Tropical evergreen broad-leaved & & Tropical deciduous broad-leaved \\
\hline & 温带常绿针叶树种3) & 温带常绿阔叶树种4) & $x$ & 温带落叶阔叶树种 \\
\hline & Temperate evergreen coniferous & Temperate evergreen broad-leaved & & Temperate deciduous broad-leaved \\
\hline & 北方常绿针叶树种5) & $x$ & 北方落叶针叶树种 & $x$ \\
\hline & Subtropical mountain cold coniferous & & Boreal summergreen coniferous & \\
\hline \multirow{6}{*}{$\begin{array}{l}\text { 灌木 } \\
\text { Shrubs }\end{array}$} & $x$ & 热带落叶灌木 & $x$ & - \\
\hline & & Hot shrubs & & \\
\hline & $x$ & 温带落叶灌木 & 温带荒漠灌木 ～～～～～～～ & - \\
\hline & & Temperate deciduous shrubs & Temperate desert shrubs & \\
\hline & 北方-高寒常绿灌木 ${ }^{6)}$ & 北方-高寒落叶灌木6） & 高寒荒漠灌木 & - \\
\hline & Alpine evergreen shrubs & Alpine deciduous shrubs & Alpine desert shrubs & \\
\hline \multirow{6}{*}{$\begin{array}{l}\text { 草 } \\
\text { Grasses }\end{array}$} & $x$ & 热带草原草 ～～～～～～ & $x$ & - \\
\hline & & Warm grasses & & \\
\hline & 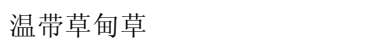 & 温带草原草 & - & - \\
\hline & Temperate meadow grasses & Temperate steppe grasses & & \\
\hline & 高寒草甸草 ～～～～～～～ & 高寒草原草 ～～～～～～～ & $x$ & - \\
\hline & Alpine meadow grasses & Alpine steppe grasses & & \\
\hline
\end{tabular}

1）国际习惯改称“热带常绿树种” The formal name is “Tropical evergreen’ 2) 国际习惯改称“热带雨绿树种” The formal name is “Tropical evergreen’ 3）包括了中国东北的常绿针叶树种 Including the evergreen conifer in northeastern of China 4）根据习惯改称“亚热带常绿树种” To be renamed as 'sub-tropical broad-leaved evergreen’ 5) 专指我国热带亚热带高山地带的常绿针叶树种 Only represent the evergreen conifer plants on Chinese tropical or subtropical mountains 6)指高海拔地带的灌木类型 Only refer to shrubs on alpines or Tibetan Plateau “ “”: 表示未入选的类型 The types that were turned off -: 同表 1 See Table 1

等, 2003$)$, 选择绝对最低温度 $\left(T_{\min }\right)$ 、最暖月平均温 度 $\left(T_{\mathrm{w}}\right)$ 、大于 $5^{\circ} \mathrm{C}$ 的有效积温 (Growing-day degrees above $5^{\circ} \mathrm{C}, G D D_{5}$ )、最暖月和最冷月的温度差 $(D T Y) 、$ 湿润指数( 年降水量和年潜在蒸散量的比 值, $P / P E T)$ 和年均降水量 $(P)$ 作为限制植物分布的 环境因子。

绝对最低温度 $\left(T_{\text {min }}\right)$ 用于区分不同树种的抗寒 性; 有效积温 $\left(G D D_{5}\right)$ 用于表示不同植物功能型的 热量需求; 湿润指数 $(M I)$ 用于限定植物的外貌。由 于高海拔地区气温低, 但太阳辐射强烈, 潜在蒸散的 计算存在问题 (慈龙骏等, 2002), 所以高寒植物功能 型首先用最暖月和最冷月温度差 $(D T Y)$ 和有效积温 $\left(G D D_{5}\right)$ 共同限定, 再用年平均降水量 $(P)$ 限定高寒 功能型的灌木和草类功能型。最暖月平均温度 $\left(T_{\mathrm{w}}\right)$ 用于表示热带亚热带灌木和草类最暖月的温 度需求。

在确定参数值时, 首先根据植物功能型分布图 (图 4) 的栅格数据 $\left(0.1^{\circ} \times 0.1^{\circ}\right)$, 用半峰宽法 $($ Peak width at half height, $P W H$ ) (徐文铎, 1983) 粗略估算 植物功能型的气候参数的最大、最小值, 其中:

半峰宽 $(P W H)=2.354 \times S$

最适范围: $[\bar{X}-1 / 2 \cdot P W H, \bar{X}+1 / 2 \cdot P W H]$

$\bar{X}$ 为环境变量的平均值, $S$ 为标准差。

然后, 再根据相关文献 (Box，1981; Woodward,
1987; Woodward \& McKee, 1991; Fang \& Yoda, 1989, 1990; 吴征镒, 1980)的研究结果初步确定各气候参 数的值; 最后, 根据所得到的各植物功能型气候参数 值确定的中国植物功能型分布图与基于《中国植被 图》确定的植物功能型的地理分布图叠加比较, 进一 步修正中国各植物功能型的气候参数值。经过反复 修正, 以达到最优, 该气候参数值即被用作划分中 国植物功能型的定量依据。

2.4 植物功能型的优势等级体系 (Dominance hierarchy) 确定

Box (1981) 为了解决植物类型的组合与植被类 型的确定的问题, 假定: 1) 植物的叶面积越大, 植株 越高, 对该地植被的贡献越大, 这些种被称为优势 种, 优势种存在不同的等级;2)在裸地上, 植被演替 将一直进行到该气候条件下可以生存的等级最高的 植物类型占优势时为止; 3 ) 植被的结构和群系类型 由优势植物类型决定。根据这个假设和实际植被中 植物类型的组成情况, 将约 100 类植物类型排列成 6 个等级, 从而构成了一个优势等级体系。这个体系 的大致顺序是: 树 $>$ 草-灌木 $>$ 极端环境植物 $>$ 裸 地, 其中树又被分为 4 个亚等级。植物功能型分布 的空间如果有重叠, 则通过植物功能型优势等级来 判断由何种植物功能型占据该空间, 即等级高者优 先, 等级相同则共存, 而等级低者则被忽略。根据 
Box(1981)的优势体系原理以及我国植被的分布, 我 们也为这些功能型规定了一个优势等级, 顺序为: 热 带树种 > 温带树种-北方树种 > 草-灌木 > 裸地。

运用等级体系本是一个权宜之计, Box（1981） 用它来表现植物间的竞争和植被的植物类型组成, 但在 Biome 系列模型 (BIOME1, Prentice et al., 1992; BIOME3, Haxeltine \& Prentice，1996）中却得到 了进一步的应用和改进。在动态植被模型中它由更 具机理性的演替子模型取代。

\section{5 植物功能型的潜在分布}

根据我国 957 个气象站点 1950 1980 年的气象 数据和海拔高程数据计算各项环境变量的值。潜在 蒸散 ( Potential evaportransipiration, PET) 用 Thornthwaite 方法计算; 先用月平均温度插值得到日平均温 度, 再计算 $G D D_{5}$ 。计算得到各站点的气候限制因 子值后, 再进行空间插值得到各栅格点的值。其中 温度计算按照海拔高度每升高 $100 \mathrm{~m}$, 温度下降 $0.6^{\circ} \mathrm{C}$ 进行订正。最后, 根据全国环境变量图判断植 物功能型的地理分布。

符合环境约束条件要求的植物功能型在一些地 区可能会有多种, 哪种功能型会存在于这一地区, 则 由它们的优势等级决定。如亚热带常绿树种在符合 热带常绿树种生长条件的地区同样也可以存在, 但 是由于热带常绿树种的优势等级比亚热带常绿树种 高, 所以后者不会存在。若优势等级相同, 这些功能 型则共存于这一区域。这样就产生了多种功能型组 合 (其中包括只含一种功能型的组合)。做图时, 每 一种功能型组合命名为一种生物群区, 从而得到生 物群区的潜在分布图。

为了评价这些生物群区的分布与我国植被分布 相吻合的程度, 我们首先根据由植物功能型得到的 生物群区类型把中国的植被区划类型重新归类, 使 它们的类型树木相同。然后用 Kappa 方法检验这两 幅图的一致性。Kappa 检验是用于评价测量目标影 像与参照影像一致性的方法 (Monserud \& Leemans, 1992; Prentice et al., 1992; 杨正宇等, 2003), 它的 意义在于忽略了 “偶发的精确”, 其计算出的误差可 以看作是在对比两幅图时的变化量。

\section{3 结果与分析}

3.1 我国的植物功能型类型及其代表种类

类型 1 . 热带阔叶常绿树种 包括台湾肉豆冦 ( Myristica cagayanensis), 白翅子树 ( Pterospermum niveum), 长叶桂木 (Artocarpus lanceolatus), 望天树
( Parashorea chinensis), 假含笑 ( Paramichelia bailloni$i$ ), 滇楠 (Phoebe nanmu) 和龙脑香属 (Dipterocarpus spp. ), 番龙眼属 (Pometia spp.), 肉豆蔻属 (Myristica spp. )等。

类型 2. 热带阔叶雨绿树种 包括木棉 (Bombax malabaricum)、楹树 (Albizia chinensis)、鸡占 ( Terminalia hainanensis)、厚皮( Lannea coromandelica) 等。 年均温 $20 \sim 25{ }^{\circ} \mathrm{C}$, 绝对最低温度 $2 \sim 5{ }^{\circ} \mathrm{C}$, 并应当出 现在旱季。

类型 3. 亚热带常绿树种 包括壳斗科栎属 ( Quercus)、化香属( Platycarya)、栲属 (Castanopsis)、 水青冈属 (Fagus)、石栎属 (Lithocarpus) 的植物。在 分类体系中, 它被命名为“温带常绿树种”, 我们根据 习惯将其改称为“亚热带常绿树种”。

类型 4. 温带落叶阔叶树种 包括华木属 ( $B e-$ tula)、杨属( Populus)、槭属（Acer）、椴树属（Tilia）、榆 属( Ulmus) 的植物。

类型 5. 温带常绿针叶树种包括云杉属 (Picea)、冷杉属 (Abies)、松属 (Pinus) 的种类。具有 忍耐 $-60{ }^{\circ} \mathrm{C}$ 低温的能力。

类型 6. 北方落叶针叶树种 主要包括落叶松 属 (Larix) 植物, 如兴安落叶松 (L. gmelinii) 和西伯 利亚落叶松 ( L. sibirica), 以及少量的红皮云杉 (Picea koraiensis)。此类植物极为耐寒, 限制它向北 分布的气候因素不是极端低温而是生长所需的积 温。它在冬天寒冷而干旱的地区比常绿针叶植物占 优势, 因为在这种气候条件下, 常绿针叶树种因缺乏 足够的积雪保护而难以忍受寒冷。

类型 7. 山地寒温性针叶树种 主要是冷杉和 云杉属的一些种类, 如鳞皮冷杉 (Abies squamata)、黄 果冷杉 (Abies ernestii) 、喜马拉雅冷杉 (Abies spectabilis)、川西云杉( Picea likiangensis var. balfouriana)、丽江云杉( Picea likiangensis) 等。与温带常绿 针叶树种不同, 它们主要分布于热带亚热带的高海 拔山区, 主要是受到西南季风湿润影响的横断山脉 南部与雅鲁藏布江中游的高山峡谷中, 那里水分充 足, 气候湿润, 但全年温凉。

类型 8. 温带落叶灌木 包括锦鸡儿( Caragana spp.)、槐 ( Sophora spp.)、薄皮木 (Leptodermis oblon$g a$ )、柽柳 (Tamarix spp.)、铃铛刺 (Halimodendron halodendron)、秀丽水柏枝 (Myricaria elegans)、蒙古柳 ( Salix mongolica) 等。

类型 9. 温带荒漠灌木 包括珍珠猪毛菜 $($ Salsola passerina)、琵琶柴( Reaumuria soongorica)、盐爪爪 
(Kalidium foliatum)、驼线藜 (Ceratoides latens)、白琐 琐 (Haloxylon persicum) 等。生于极端干旱的环境, 或 有地下水补充。

类型 10. 热带-亚热带灌木 包括乌饭树 (Vaccinium bracteatum)、映山红 (Rhododendron simsii) 等。 分布在热带、亚热带丘陵低山的灌丛, 就其外貌看 来, 有常绿的也有落叶的, 性喜暖热, 不耐寒冷。

类型 11. 高山亚高山常绿灌木 包括常绿革叶 灌木和常绿针叶灌木, 主要是杜鹃属 (Rhodondendron) 和圆柏属 (Sabina) 的植物, 如钟花杜鹃 ( Rhodondendron campanulatum)、宏钟杜鹃 ( R. wighti$i$ )、雪层杜鹃 ( $R$. nivale)、香柏 (Sabina pingii var. wilsonii)、高山柏 ( $S$. squamata)、滇藏方枝柏 $(S$. wallichiana) 等。主要分布于森林区及其外缘地带的 亚高山带上部和高山带, 生境湿润而寒冷。

类型 12. 高寒落叶灌木 包括圆叶华 (Betula rotundifolia)、毛枝山居柳 ( Salix oritrepha)、杯腺柳 ( $S$. cupularis)、光叶柳 ( $S$. rehderiana var. glabra)、 藏矮柳 $(S$. resectoides $) 、$ 硬叶柳 $(S$. sclerophylla $) 、$ 箭 叶锦鸡儿( Caragana jubata)、金露梅 (Dasiphora fruticosa) 、藏沙棘 (Hippophae tibetica)、匍匐水柏枝 (Myricaria prostrata) 等。广布于高原和高山带的山坡、谷 地以及河谷。

类型 13. 高寒荒漠灌木 包括垫状驼线藜 (Ceratoides compacta)、无茎芥 ( Pegaeophyton scapiflorum)、藏芥 (Hedinia tibetica)、藏棘豆 (Oxytropis tibeti$c a$ )、藏亚菊 (Ajania tibetica) 等。这些植物主要分布 于青藏高原西北部, 海拔 $4600 \sim 5500 \mathrm{~m}$, 气候寒冷 而干旱。

类型 14. 温带草甸草 包括贝加尔针茅 ( Stipa baicalensis)、羊草 (Aneurolepidium chinense)、线叶菊 (Filifolium sibiricum)、芨苃草 (Achnatherum splendens)、獐茅( Aeluropus littoralis) 等典型中生植物。适 应于中温、中湿环境。

类型 15. 温带草原草 包括针茅属 (Stipa) 的 许多植物, 如大针茅 ( $S$. grandis)、克氏针茅 $(S$. krylovii) 和羊茅 (Festuca ovina)、糙隐子草 (Cleistogenes squarrosa)、冰草 (Agropyron cristatum)、冷蒿 (Artemisia frigida) 等。分布于干旱、半干旱地区。

类型 16. 稀树草原草 指生长在亚热带干热地 区的多年生草本植物, 它们耐旱、耐贫㾑、耐火烧, 如 扭黄茅( Heteropogon contortus)、华三芒草( Aristida chinensis)、丈野古草 (Arundinella decempedalis)、龙须草 (Eulaliopsis binata) 等。此类植物主要分布在我国热
带亚热带地区山地背风面的雨影区, 如西南山区的 干热河谷中。由于我国热带亚热带地区降水量丰 沛, 所以这种类型在我国分布并不广。

类型 17. 高寒草甸草 包括小嵩草 (Kobresia pygmaea)、西伯利亚斗篷草 (Alchemilla sibirica)、圆穗 鉁( Polygonum sphaerostachyum) 等。分布于高寒、中 湿, 日照充足, 太阳辐射强的地区。

类型 18. 高寒草原草 指非常耐寒的高寒旱生 矮草本植物, 如紫花针茅 ( Stipa purpurea)、羽柱针茅 ( Stipa subsessiliflora var. basiplumosa)、座花针茅 ( Stipa subsessiliflora)、硬叶苔草( Carex moorcroftii)、银穗 羊茅( Festuca olgae) 等。多生于青藏高原腹地海拔 $4000 \mathrm{~m}$ 以上寒冷而干旱的地区。

为了应用方便, 根据成因将裸地分为两种:

类型 19. 干旱裸地 指盐壳、流动沙丘、裸露戈 壁、裸露石山。

类型 20. 高寒裸地 指高山碎石、倒石碓和冰 川雪被。

这套 18 类的功能型体系包括了树、灌木和草类 三大类, 其中含有为了青藏高原以及其它高山地区 植被模拟的需要而专门设置的 6 种高山-高寒植物 功能型。

高大乔木功能型 我国东部植被分布明显呈现 出纬向地带性, 形成了世界上最大的连续不间断分 布的森林植被, 可以作为研究全球植被气候系统和 全球自然地理纬向地带性的参照 (Fang et al., 2002)。将我国东部森林带的植物功能型由南向北 分为 6 类: 类型 1 -热带阔叶常绿树种、类型 2-热带阔 叶雨绿树种、类型 3-亚热带常绿树种、类型 4-温带落 叶阔叶树种、类型 5-温带常绿针叶树种、类型 6-北方 落叶针叶树种。由于青藏高原东南部高山地区存在 大量以云杉和冷杉为主的针叶林, 所以增设类型 7山地寒温性针叶树种。它们的分布区海拔高, 气候 常年气候温凉, 且降水量大。

灌木类功能型 灌丛的生态适应幅度较森林 广, 在气候过于干燥或寒冷, 高大树木难以生存的地 方, 则有灌丛分布。灌从在我国植被水平分布带中 并未占有显著地位。这是由于我国东半壁气候湿 润, 发育了大面积的森林; 西南部又有青藏高原的隆 起, 产生了一套高原植被; 西北部荒漠中虽有灌丛存 在, 但面积不大, 而且植被稀疏, 常被作为荒漠处理 （Hou，1983）。我国是多山的国家, 在山地垂直带上 常有原生灌从的分布。在长期的人类经济活动影响 下, 也发生了许多次生性的灌丛类型。本文将全部 


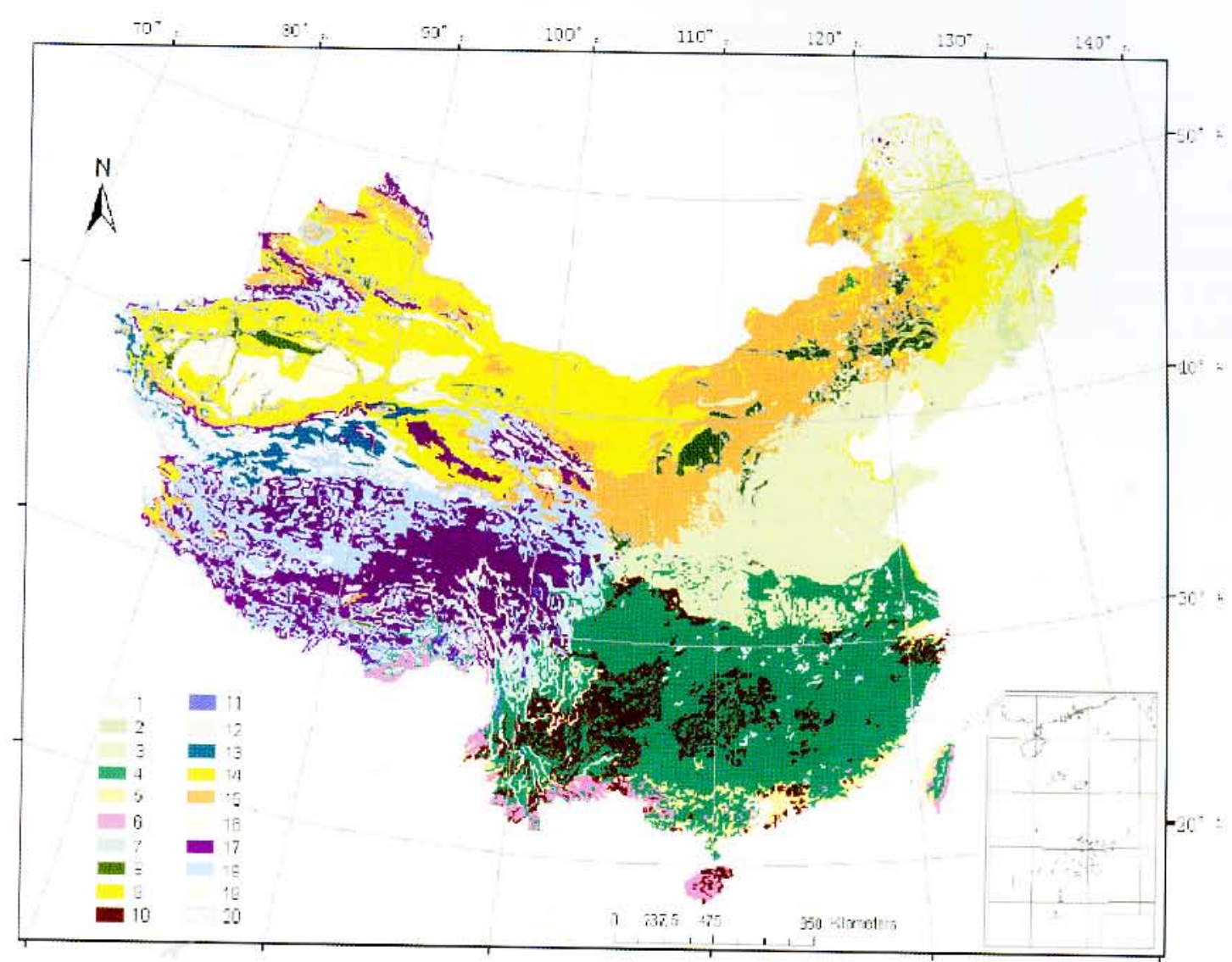

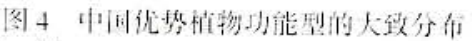

Fig.4 The approximate distritution of PFT's of China

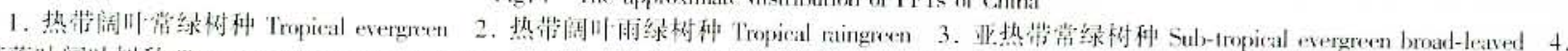

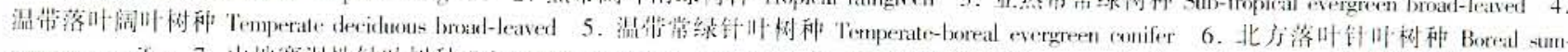

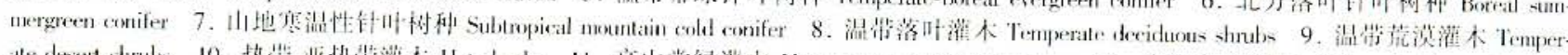

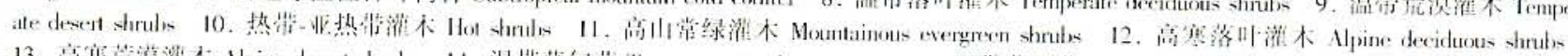

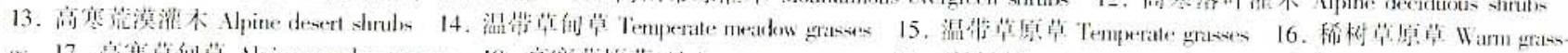

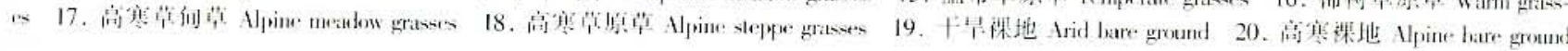

灌木划分为 6 种类型,包括:类型 8 -温带落川阔叶灌 木、类型9-温带葫漠灌木、类型10-热带-业热带灌 木、类型11-高山常绿灌木、类型12-高寒落叶灌木、 类型13-宲寒范漠灌木

草类功能型分为 5 类: 类型14-湿带草何草、 类型15-温带草原草、类型16-桸树草原草以及类型 17-高寒草向草和类型18-高基草原草。类型 14 和 类型 15 是我国草原地区的优势植物类型，二者最大 约区别在于水分的需求不问 类型16 只你在与我 国西南山区的山谷り, 那里干热少雨, 定义类型 16 主装是考虑到将来我国热带一业热带地区气候如果 趋问干早或原住生态系统受到人类活动的十抗后, 它的分们范围将有护大的可能

宫寒类功能型 高寒类功能犁包括类型11-高 山亚高川常绿灌木、类型12-高寒落川灌木、类型13高寒苝漠灌木、类型17-高寒草伆草、类型18-高寒草 原草, 共 5 种。直践高原们隆起对枮被分布造成了
「大的影响(Chang, 1983), 这此功能型是为研究青 藏宲原的植被分布规律及其与分候的关系面定义 的高山植物因其牛长环境的特殊面形成了一系列 特姝约适应机例(Körner，1999)，其中最主要的是生 埋 上:的抗寒性和抗早性( Tranquillini, 1964)

3.2 植物功能型分布的坏境限制参数

各植物功能型的环境限制参数值如衣 3 所示 表 3 中不是昌: 一项都石值。每类植物功能型只要满 足它分布的气候限制条件, 就可能在此气候下存在 如, “热需常绿树种”一栏只有 “ $T_{\min }>5$ ”和 “ $M I>$ 1.2”两个限制条件, 这意味着, 只姴满足最冷月平均 温度大于 $5{ }^{\circ} \mathrm{C}$ 和全年平均湿润指数大于 1.2 , 热带 常绿树种就可以存在 枮物功能型的俣限制因子 规定了功能型你在的气候空间。每个功能型只存在 于自己的气候空间中, 当不同功能型的气候空间存 在重叠时, 则由植物功能型的优势等级 (D) 决定谁 将你在: 
表 3 各植物功能型的环境限定因子和优势等级

Table 3 Climatic constraints and dominance class for PFTs of China

\begin{tabular}{|c|c|c|c|c|c|c|c|}
\hline $\begin{array}{c}\text { 植物功能型 } \\
\text { Plant functional types }\end{array}$ & $T_{\min }\left({ }^{\circ} \mathrm{C}\right)$ & $G D D_{5}$ & $T_{\mathrm{w}}\left({ }^{\circ} \mathrm{C}\right)$ & DTY & $M I$ & $P(\mathrm{~mm})$ & $\mathrm{D}$ \\
\hline \multicolumn{8}{|l|}{ 树 Trees } \\
\hline 1 热带阔叶常绿树种 Tropical evergreen & $>5$ & & & & $>1.2$ & & 1 \\
\hline 2 热带阔叶雨绿树种 Tropical raingreen & $>5$ & & & & $1 \sim 1.5$ & & 1 \\
\hline $\begin{array}{l}3 \text { 亚热带常绿树种 Sub-tropical evergreen } \\
\text { broad-leaved }\end{array}$ & $>-10$ & $>3300$ & & & $>0.8$ & & 2 \\
\hline $\begin{array}{l}4 \text { 温带落叶阔叶树种 Temperate deciduous } \\
\text { broad-leaved }\end{array}$ & $-50 \sim-8$ & >1200 & & $>30$ & 0.7 & & 2 \\
\hline $\begin{array}{l}5 \text { 温带常绿针叶树种 Temperate-boreal ever- } \\
\text { green conifer }\end{array}$ & $-60 \sim-10$ & $>900$ & & $>20$ & $>0.7$ & & 2 \\
\hline $\begin{array}{l}6 \text { 北方落叶针叶树种 Boreal summergreen } \\
\text { conifer }\end{array}$ & $<-30$ & $>350$ & & $>20$ & $>0.7$ & & 2 \\
\hline $\begin{array}{l}7 \text { 山地寒温性针叶树种 Subtropical mountain } \\
\text { cold conifer }\end{array}$ & & $1200 \sim 2700$ & & $<20$ & $>1$ & & 3 \\
\hline \multicolumn{8}{|l|}{ 灌木 Shrubs } \\
\hline 8 温带落叶灌木 Temperate deciduous shrubs & & $>900$ & & $>30$ & $>0.5$ & & 4 \\
\hline 9 温带荒漠灌木 Temperate desert shrubs & & $>1350$ & & $>30$ & $0.1 \sim 0.5$ & & 4 \\
\hline 10 热带-亚热带灌木 Hot shrubs & $>-10$ & $>4000$ & $>30$ & & $<1.2$ & & 5 \\
\hline $\begin{array}{l}11 \text { 高山常绿灌木 Mountainous evergreen } \\
\text { shrubs }\end{array}$ & & $300 \sim 1600$ & & $<20$ & & $>350$ & 6 \\
\hline 12 高寒落叶灌木 Alpine deciduous shrubs & & $300 \sim 1600$ & & $<25$ & & $>120$ & 6 \\
\hline 13 高寒荒漠灌木 Alpine desert shrubs & & $<1350$ & & $<30$ & & $<120$ & 7 \\
\hline \multicolumn{8}{|l|}{ 草 Grasses } \\
\hline 14 温带草甸草 Temperate meadow grasses & & $>900$ & & $>30$ & $>0.6$ & & 4 \\
\hline 15 温带草原草 Temperate grasses & & $900 \sim 4000$ & & & $>0.3$ & & 4 \\
\hline 16 稀树草原草 Warm grasses & $>-10$ & $>4000$ & $>30$ & & $0.3 \sim 0.8$ & & 5 \\
\hline 17 高寒草甸草 Alpine meadow grasses & & $500 \sim 1600$ & & $<30$ & & $>350$ & 6 \\
\hline \multicolumn{7}{|l|}{ 裸地 Bare grounds } & 6 \\
\hline 19 干旱裸地 Arid bare ground & & & & & $<0.05$ & & 8 \\
\hline 20 高寒裸地 Alpine bare ground & & $<50$ & & & & & 8 \\
\hline
\end{tabular}

$T_{\text {min }}$ : 绝对最低温度 Absolute minimum temperature $T_{\mathrm{w}}$ : 最暖月平均气温 Temperature of warmest month $G D D_{5}$ : 大于 $5{ }^{\circ} \mathrm{C}$ 的有效积温 $\mathrm{Growing}$ day degrees above $5{ }^{\circ} \mathrm{C} \quad D T Y$ : 年最热月平均温和最冷月平均温之差 Annual range of monthly mean temperature $\quad M I$ : 湿润指数 Moisture index $P$ : 年 降水量 Annual precipitation D: 优势等级 Dominance hierarchy

\section{3 植物功能型的潜在分布}

根据表 3 确定的植物功能型存在的气候空间 (Climatic envelopes), 这 18 种植物功能型在中国当前 气候条件下的地理分布存在 15 种组合方式, 我们将 其命名为 15 种生物群区 (表 4)。将根据功能型分 布得到的生物群区分布图(图 5)与中国植被图进行 Kappa 检验, 得到的总 Kappa 值为 0.67 , 达到了“ “很 好”的程度。各生物群区的 Kappa 值从 $0.25 \sim 0.88$ 不等。这个结果表明, 这套植物功能型完全可以模 拟我国的植被分布。

\section{4 讨 论}

植物功能分类源于植物群落与环境关系的研究 (Grime，2001),这种分类一开始就注定要与特定的 研究目的和背景相联系。在各自的研究目的和尺度
中, 研究者们使用了不同的术语, 如突出群( Emergent groups)、植物策略 (Plant strategies)、植物功能型 (Plant functional types) 以及响应群 (Specific response groups) 等( Lavorel et al.，1997)。在区域或全球尺度的研究 中, 通常把通过相同的方式响应环境因子, 在生态系 统过程中有着相同的角色的植物种类称为“植物功 能型”。在实践中, 植物功能型的划分带有很强的主 观性, 并往往受限于研究者的知识背景和植物特征 与环境梯度的选择。

植物功能分类在全球变化研究中得到广泛重视 是最近 10 余年的事。引入植物功能型概念的目的 主要在于削减研究对象的复杂性。最初, 人们期望 能够得到一套全球适用的植物功能型。GCTE 的 PFTs 工作组的一个任务就是建立一套单一的、可在 全球尺度通用的“关键” 植物功能型, 这套功能型应 
表 4 优势植物功能型的组合和生物群区命名

Table 4 Combinations of dorminant PFTs and the names they were given for mapping

\section{Combinations of PFTs}

热带阔叶常绿树种 Tropical evergreen trees

热带阔叶雨绿树种 Tropical raingreen trees

热带阔叶雨绿树种 Tropical raingreen trees

亚热带常绿树种 Sub-tropical evergreen broad-leaved trees

亚热带常绿树种 Sub-tropical evergreen broad-leaved trees 温带落叶阔叶树种 Temperate deciduous broad-leaved trees

温带落叶阔叶树种 Temperate deciduous broad-leaved trees

温带常绿针叶树种 Temperate-boreal evergreen needle-leaved

温带落叶阔叶树种 Temperate deciduous broad-leaved

温带常绿针叶树种 Temperate-boreal evergreen needle-leaved

北方落叶针叶树种 Boreal summergreen needle-leaved

北方落叶针叶树种 Boreal summergreen needle-leaved

温带-北方常绿针叶树种 Temperate-boreal evergreen needle-leaved trees

山地寒温性针叶树种 Subtropical alpine cold needle-leaved

温带草甸草 Temperate meadow grass

温带草原草 Temperate steppe grass

温带落叶阔叶灌木 Temperate deciduous shrub

温带草原草 Temperate steppe grass

温带落叶阔叶灌木 Temperate deciduous shrub

温带草原草 Temperate steppe grass

温带荒漠灌木 Temperate desert shrub

温带荒漠灌木 Temperate desert shrubor

干旱裸地 Arid bare grounds

高寒草甸草 Alpine meadow grass

高山常绿灌木 Mountain evergreen shrub

高寒落叶阔叶灌木 Alpine deciduous shrub

高寒草原草 Alpine steppe grass

高寒落叶阔叶灌木 Alpine deciduous shrub

高寒荒漠灌木 Alpine desert shrubor

高寒裸地 Cold bare grounds
Biomes

1 热带雨林 Tropical rain forest

2 热带季雨林 Tropical seasonal forest

3 亚热带常绿阔叶林 Sub-tropical evergreen broad-leaved forest

4 温带常绿落叶阔叶混交林 Mixed deciduous-evergreen broad-leaved forest

5 温带落叶阔叶林 Temperate deciduous forest

6 温带针阔叶混交林 Temperate mixed broad-leaved and coniferous forest

7 北方针叶林 Boreal coniferous forest (Taiga)

8 亚热带山地寒温性针叶林 Sub-tropical mountainous cool coniferous forest

9 温带草甸草原 Temperate meadow-woodland

10 温带典型草原 Temperate typical steppe

11 温带荒漠草原 Temperate desert steppe

12 温带荒漠 Temperate desert

13 高寒灌丛草甸 Alpine meadow

14 高寒草原 Alpine steppe

15 高寒荒漠 Alpine desert
当可以用于描述全球的植物种类和植被对环境变化 的反应(Steffen et al., 1992)。但许多研究却表明这 种思路是不可行的 (Cramer et al., 1999), 因为:

1) 将植物种类归入功能型是对现实的简化, 这 样功能型的定义就依赖于特定研究的背景、尺度和 要解决的问题。一个生物地球化学模型有着对光合 途径的考虑, 可能需要对 $\mathrm{C}_{3}$ 和 $\mathrm{C}_{4}$ 植物进行区分, 而 生物地理模型则不需要。

2) 植物的功能属性是不容易鉴别的, 根据可见 的结构特征划分得到的功能型可能并不必然就是植 物的功能型分类, 植物的一些生理特征并不在结构 上表现出来(Box, 1996; Woodward \& Kelly, 1997)。 如根据植物结构划分的功能型无法预测植物对 $\mathrm{CO}_{2}$ 增加的反应。这些情况对评估植物功能型的各个特 征对全球变化的反应是很大的障碍, 在定义植物功 能型时,需要特别加以关注。

但无论如何, 现在已经有了许多功能型分类的
例子, 它们对全球变化的情形有着一定的预测能力 (Box, 1996), 众多的分类方案在植物关键特征的选 择上也逐渐趋同, 得到的类型也越来越有可比性 （Cramer et al.，2001）。这些成功的方法同时也表明 植物的功能分类对研究的尺度、背景和问题的高度 依赖性。

有鉴于此, 本文提出了一个步骤明晰、具有理论 基础和可扩展性的植物功能型划分方法。这个方法 在选择关键植物属性的基础上, 进行了一个两步骤 的功能型划分。这个方法主要源自 Running 等 (1995) 基于遥感数据的植被类型划分逻辑以及 Box (1981，1995) 和 Woodward（1987）的原理和方法。 $\operatorname{Box}(1981)$ 曾给出了一个详尽的全球植被的功能型 划分, 它包括了 93 类植物类型, 囊括了几乎所有的 植物外貌类型。Woodward（1987）指出了植物分布 的气候限制的生理学机理。Prentice 等(1992)在此 基础上, 选择了一套只含 14 个类型的优势植物功能 


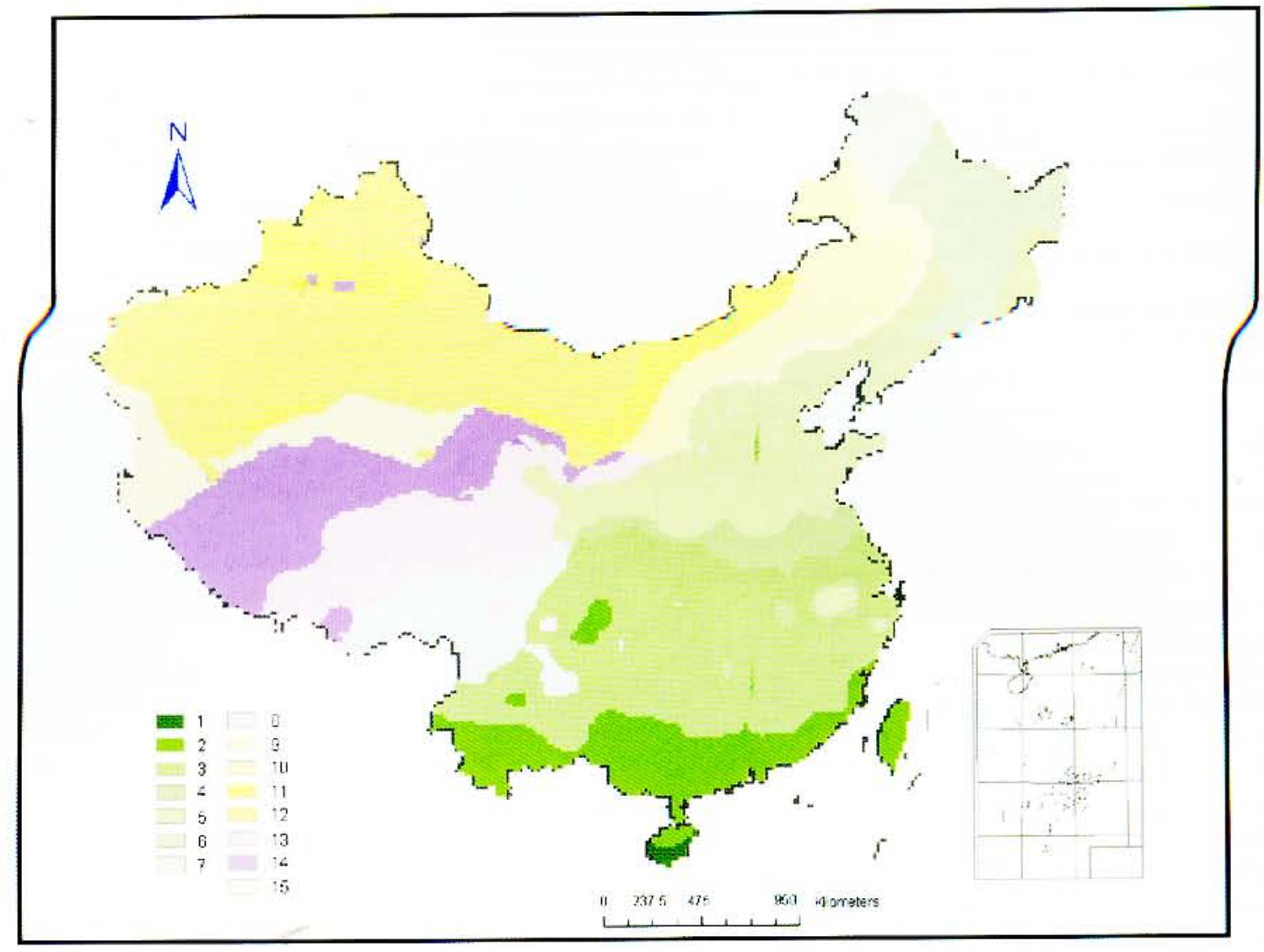

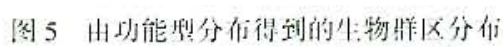

Fig.5 Biome map derived from PFT.

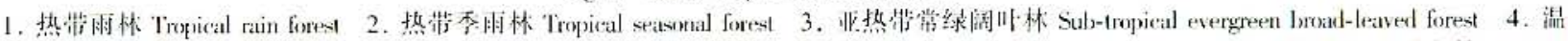

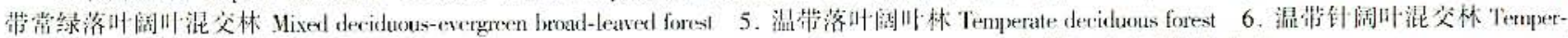

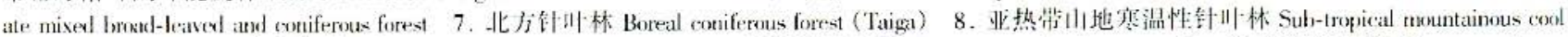

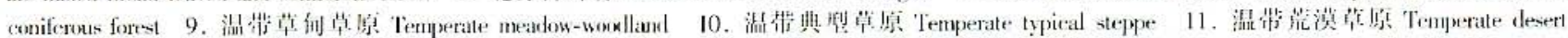

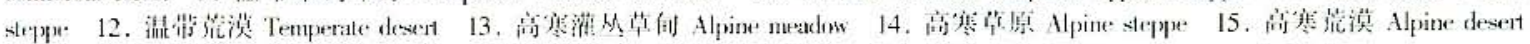

型体系并用具有明确牛理学意义的环境因素作为功 能型分布的限制性、恩子进行全球生物群区模拟。 Running 等 (1995) 根据植被模拟需婪和遥感数据的 识别能力, 提记了一个基于遥感数据的植被层次分 类逻辑, 其主荘的依据是可被了星感知的植被远层 特征。Running 的方法被应用到了生态系统功能模 型中(Nemani \& Running, 1996)

根据本文的方法所得到的这 29 类备选类型弁 不能震括全部的植物利类, 但它可以将主要的植物, 特别是那些决定植被类型和陆地表面生物物理利生 物地球化学特征的关键植物种类, 归人到这些功能 类型中来，从而使这一整会植物功能型足以反咉地 表的生物地理、生物物理和生物地球化学特征。这 个方法可应用于区域尺度的㥀物功能型划分和笚 选, 所得到的植物功能型可应用于植被地理分布、生 物地球化兴以及植被一大气相丝作用的研究。

需要指出,按本文所选的关键特征组合表示出
来的一此植物功能类型并没乍相监的植物种类与它 相对应, 如北方常绿阔叶树种, 就没有相应的植物种 类。我们也将它列到表中, 仅表示份在这种功能组 合, 并不认为现实的不境中当然存在这种类型的植 物。只外, 对灌木的划分应当随着对“树”的划分一 并进行, 得到与“树”同样数目 (12 类) 的灌木和荒漠 濯木类型。但是, 由于灌木的定义不够清晰, 且类型 复杂多样, 许多模型的功能型划分方案对灌木类型 做了简化处理,甚至不使用单独的灌木类功能型, 它 的功能由树或草代表( Haxeline \& Prentice, 1996)。 为了方便, 我们对灌木类型的划分也做了很大的简 化。对灌木不再区分针听-阔叶, 这样只有 6 类; 而 对茫漠灌木不区分针叶-阔叶和常绿-落叶, 这样只 得到 3 类。

尽管我们为其中的 18 类植物功能型选择了代 表植物, 植物功能型还是不能被看作是具体的植物 体, 而只能被认为是模式化的植物, 代表着所选关键 
特征的功能组合。对于每类功能型, 应当只从这些 关键特征的视角去审视, 而忽略掉具体植物的其它 多样而又复杂的特征。作为研究大尺度植被-气候 相互作用的植物功能型划分, 我们只考虑了 6 项关 键植物特征。这些特征在大的尺度上决定植被外貌 和功能, 并影响着陆地-大气的相互作用。它们当然 不足以详尽地描述植被的动态以及植物与环境相互 作用。根据研究尺度和目的的不同, 研究者们也会 选用不同的特征,划分出不同的功能型, 以满足各自 的研究需要。

选择这 18 类功能型有着对我国植被-气候状况 的现实考虑。我国是一个季风气候强盛和地貌类型 复杂的国家, 植被分布有其独特性 ( $\mathrm{Hou}, 1983$ )。东 部和西南部地区季风活动强盛, 夏季从太平洋吹来 的东南季风和来自印度洋的西南季风, 带来了丰富 的降水,造就了东部和西南部温暖而湿润的气候。 虽冬季寒冷而干旱, 但雨热同期有利于植物生长。 西北内陆地区则因远离海洋且有高山阻挡, 气候干 燥少雨。这样,由东向西构成湿润、半湿润、半干旱、 干旱的水分气候序列, 植被表现出森林、森林草原、 草原和荒漠的径向地带性。我国西南部青藏高原的 高高隆起打破了中国低地地区的植被水平分布规 律, 并形成了独特的高寒景观 (Chang, 1983)。特别 是南部边缘喜马拉雅山脉的阻挡, 使得西南和东南 气流只能从东南部” 缺口”处进入高原, 造成水分从 东南向西北由多到少的变化, 从而决定了高原植被 分布从东南向西北更替, 它们依次为高山亚高山森 林、高寒草甸、高寒草原和高寒荒漠。我们进行功能 型划分时也主要考虑了这 2 个因素: 季风气候和青 藏高原, 因为它们主导着中国植被的分布。

与 van Minnen 等(1996)和倪健 (2001)的方案相 比较, 本文选择的含 18 类功能型的方案在充分反映 我国气候-植被特征的基础上进一步简化了植物功 能型的数目, 并根据文献记载和植物的地理分布给 出了功能型分布的气候限制参数, 使之更具有实用 价值。这 18 类植物功能型能够代表我国主要植被 类型及其优势植物种类的结构和功能特征以及我国 的植被-气候特征, 并且类型数目适中, 便于参数化 和实际应用。它可以用于研究我国气候-植被的相 互作用; 可用于研究植被与大气之间的物质(如水和 二氧化碳等)和能量(如太阳辐射、动量和热量等)的 交换; 也可以用于生态系统模型向区域植被模型的 转换; 从而为建立适用于中国的区域植被动态模型 和区域气候模型提供了基础。

\section{参 考 文 献}

Becker P (2000). Competition in the regeneration niche between conifers and angiosperms, Bond's slow seedling hypothesis. Functional Ecology, 14, 40-412.

Becker P, Meinzer FC, Wullschleger SD(2000). Hydraulic limitation of tree height, a critique. Functional Ecology, 14, 4-11.

Beerling DJ, Woodward FI(1996). Paleo-ecological perspectives on plant responses to global change. Trend in Ecology and Evolution, $11,20-23$.

Bonan GB(1995) . Land-atmosphere interactions for climate system models, coupling biophysical, biogeochemical, and ecosystem, dynamical processes. Remote Sensing of Environment, 51, 57 73.

Bonan GB(1996) . A Land Surface Model (LSM Version 1.0) for Ecological, Hydrological and Atmospheric, Technical Description and User's Guide, NCAR Technical Note NCAR-TN-417 + STR. National Center for Atmospheric Research, Boulder.

Bonan GB, Levis S, Kergoat L, Oleson KW(2002). Landscapes as patches of plant functional types: an integrating concept for climate and ecosystem models. Global Biogeochemical Cycles, 16, 10. 1029-2000GB001360.

Bonan GB, Levis S, Sitch S, Vertenstein M, Oleson KW (2003). A dynamic global vegetation model for use with climate models: concepts and description of simulated vegetation dynamics. Global Change Biology, 9, 1543 - 1566.

Botkin DB, Jansk JF, Wallis JR(1972). Some ecological consequences of computer model of forest growth. Journal of Ecology, $60,869-872$.

Box EO(1981). Macroclimate and Plant Forms: an Introduction in Predictive Modeling in Phytogeography. Dr. Junk W, The Hague.

Box EO(1995). Factors determining distributions of tree species and plant functional types. Vegetatio, 121, $101-116$.

Box EO (1996). Plant functional types and climate at the global scale. Journal of Vegetation Science, 7, $309-320$.

Chang HS(1983). The Tibetan plateau in relation to the vegetation of China. Annals of the Missouri Botanical Garden, 70, 564 570 .

Christopher HL, Wright I, Reich PB(2003) . Photosynthetic differences contribute to competitive advantage of evergreen angiosperm trees over evergreen conifers in productive habitats. New Phytologist, $160,329-336$.

Ci LJ(慈龙骏), Yang XH(杨晓辉), Chen ZX (陈仲新) (2002). The potential impacts of climate change scenarios on desertification in China. Earth Science Frontiers (地学前缘), 9, 287 294. (in Chinese with English abstract)

Cornelissen JHC, Castro DP, Hunt R(1996). Seedling growth, allocation and leaf attributes in a wide range of woody plant species and types. Journal of Ecology, 84, 755-765.

Cramer W(1997). Using plant functional types in a global vegetation model. In: Smith TM, Shugart HH, Woodward FI eds. Plant Functional Types: Their Relevance to Ecosystem Properties and Global Change. Cambridge University Press, Cambridge, $271-288$.

Cramer W, Bondeau A, Woodward FI, Prentice IC, Betts RA, Brovkin V, Cox PM, Foley JA, Friend AD, Kucharik C, Lomas 
MR, Ramankutty N, Sitch S, Smith B, White A, Christine YM (2001). Global response of terrestrial ecosystem structure and function to $\mathrm{CO}_{2}$ and climate change: results from six dynamic global vegetation models. Global Change Biology, 7, 357 - 373 . Cramer W, Shugart HH, Noble IR, Woodward FI, Bugmann H, Bondeau A, Foley JA, Gardner RH, Lauenroth WK, Pitelka LF, Sutherst RW(1999). Ecosystem composition and structure. In: Walker B, Steffen W, Canadell J, Ingram J eds. The Terrestrial Biosphere and Global Change - Implications for Natural and Managed Ecosystems. Cambridge University Press, Cambridge, $190-228$.

Eamus D, Cole S(1997). Diurnal and seasonal comparisons of assimilation, phyllode conductance and water potential of three $A$ cacia and one Eucalyptus species in the wet-dry tropicas of Australia. Australia Journal of Botany, 45,275 - 290 .

Eamus D(1999). Ecophysiological traits of deciduous and evergreen woody species in the seasonally dry tropics. Trends in Ecology and Evolution, 14, $11-16$.

Ehrlen J, Lehtila K(2002). How perennial are perennial plants. Oikos, 98, $308-322$.

Enright NJ, Bartlett RM, de Freitas CR(1993). Patterns of species composition, recruitment, and growth within canopy gaps in two New Zealand kauri (Agathis australis) forests. New Zealand Journal of Botany, 31, 361-373.

Fang JY, Yoda K(1989) . Climate and vegetation in China II. Distribution of main vegetation types and thermal climate. Ecological Research, 4, $71-83$.

Fang JY, Yoda K(1990) . Climate and vegetation in China III. Water balance and distribution of vegetation. Ecological Research, $5,9-23$

Fang JY(方精云) (2001). Re-discussion about the forest vegetation zonation in eastern China. Acta Botanica Sinica (植物学 报), 43, 522 - 533. (in Chinese with English abstract)

Fang JY, Song YC, Liu HY, Piao SL(2002). Vegetation-climate relationship and its application in the division of vegetation zone in China. Acta Botanica Sinica (植物学报), 44, 1105 - 1122 .

Foley JA, Prentice IC, Ramankutty N, Levis S, Pollard D, Sitch S, Haxeltine A (1996). An integrated biosphere model of land surface processes, terrestrial carbon balance, and vegetation dynamics. Global Biogeochemical Cycles, 10, 603-628.

Foley JA, Samuel L, Prentice IC, Pollard D, Thompson SL (1998). Coupling dynamic models of climate and vegetation. Global Change Biology, 4, $561-579$.

Franco AD (1998). Seasonal patterns of gas exchange, water relations and growth of Roupala montana, an evergreen savanna species. Plant Ecology, 136, $69-76$.

Friend AD(1993). The prediction and physiological significance of tree height. In: Solomon AM, Shugart HH eds. Vegetation Dynamic and Global Change. Chapman \& Hall, London, 101 115 .

Friend AD, Stevens AK, Knox RG, Cannell MGR(1997). A process-based, terrestrial biosphere model of ecosystem dynamics (HYBRID v3.0) . Ecological Modelling, 95, 249-287.

Gallimore RG, Kutzbach JE (1996). Role of orbitally induced changes in tundra area in the onset of glaciation. Nature, 381, $503-505$

Gitay H, Noble IR (1997). What are functional types and how should we seek them. In: Smith TM, Shugart HH, Woodward FI eds. Plant Functional Types: Their Relevance to Ecosystem Properties and Global Change. Cambridge University Press, Cambridge, $3-19$.

Grime JP(2001). Plant Strategies, Vegetation Processes, and Ecosystem Properties 2nd edn. John Wiley \& Sons, Chichester, 3 -10 .

Haxeltine A, Prentice IC(1996). BIOME3: an equilibrium terrestrial biosphere model based on ecophysiological constraints, resource availability, and competition among plant functional types. Global Biogeochemical Cycles, 10, 693-709.

Haxeltine A, Prentice IC, Creswell ID (1996). A coupled carbon and water flux model to predict vegetation structure. Journal of Vegetation Science, 7, 651-666.

Hou XY (侯学煜) (1982). Vegetation Map of People's Republic of China (1:400 million) (中国植被图集). Map Press, Beijing. (in Chinese)

Hou HY (1983). Vegetation of China with reference to its geographical distribution. Annals of the Missouri Botanical Garden, 70, $509-548$.

IPCC(2001). Climate Change 2001 : the Scientific Basis. Contribution of WG1 to the Third Assessment Report of the Inter-Government Panel on Climate Change. Cambridge University Press, Cambridge, UK.

James RE, Cerling TE(2002) . $\mathrm{C}_{3}$ and $\mathrm{C}_{4}$ Photosynthesis. In: Munn $\mathrm{T}$ ed. Encyclopedia of Global Environmental Change, Vol. 2 the Earth System: Biological and Ecological Dimensions of Global Environmental Change (Mooney HA, Canadell JG eds.). John Wiley \& Sons, Chichester, $186-190$.

Kienast F (1987). FORECE - A Forest Succession Model for Southern Central Europe. Oak Ridge National Laboratory, Oak Ridge, Tennessee, ORNL-TM-10575.

Kittel TGF, Steffen WL, Chapin FS III(2000). Global and regional modelling of Arctic-boreal vegetation distribution and its sensitivity to altered forcing. Global Change Biology, 6(Suppl. 1), 1 18 .

Körner C(1999) . Alpine Plant Life - Functional Plant Ecology of High Mountain Ecosystems. Springer-Verlag, Berlin, 221 - 246.

Lavorel S, Mclntyre S, Landsberg J, Forbes TDA (1997). Plant functional classifications: from general groups to specific groups based on response to disturbance. Trends in Ecology and Evolution, $12,474-478$.

Lusk CH, Matus F (2000). Juvenile tree growth rates and species sorting on fine-scale soil fertility gradients in a Chilean temperate rain forest. Journal of Biogeography, 27, $1011-1020$.

Monserud RS, Leemans R (1992). Comparing global vegetation maps with the Kappa statistics. Ecological Modelling, 62, 275 293.

Nemani R, Running SW (1996). Implementation of a hierarchical global vegetation classification in ecosystem function models. Journal of Vegetation Science, 7, 337 - 346.

Ni J(倪健) (2001). Plant functional types and biomes of China at a regional scale. Acta Botanica Sinica (植物学报), 43, 419 425. (in Chinese with English abstract)

Ni J(2002) . Plant functional types and climate along a precipitation gradient in temperate grasslands, north-east China and south-east Mongolia. Journal of Arid Environments, 53, $501-516$. 
Prentice IC, Cramer W, Harrison SP, Leemans R, Monserud RA, Solomon AM(1992) . A global biome model based on plant physiology and dominance, soil properties and climate. Journal of Biogeography, 19, $117-134$.

Read J(1995) . The importance of relative growth rates in determining the canopy composition of Tasmanian rainforest. Australian Journal of Botany, 43, 243-271.

Reich PB, Walters MB, Ellsworth DS(1992). Leaf life-span in relation to leaf, plant, and stand characteristics among diverse ecosystems. Ecological Monography, 62, 365-392.

Robinson JM ( 1994). Speculations on carbon dioxide starvation, Late Tertiary evolution of stomatal regulation and floristic modernization. Plant, Cell \& Environment, 17, 345 - 354 .

Running SW, Gowder ST(1991). FOREST-BGC, a general model of forest ecosystem processes for regional applications. II. Dynamic carbon allocation and nitrogen budgets. Tree Physiology, $9,147-160$.

Running SW, Loveland TR, Pierce LL, Nemani RR, Hunt Jr ER (1995) . A remote sensing based vegetation classification logic for global land cover analysis. Remote Sensing of Environment, 51, $39-48$.

Sellers PJ, Mintz Y, Sud YC, Dalcher A (1986). A simple biosphere model ( $\mathrm{SiB})$ for use within general circulation models. Journal of Atmospheric Sciences, 43, 505 - 531 .

Sitch S, Smith B, Prentice IC, Arneth A, Bondeau A, Cramer W, Kaplan JO, Levis S, Lucht W, Sykes MT, Thonicke K, Venevsky S(2003). Evaluation of ecosystem dynamics, plant geography and terrestrial carbon cycling in the LPJ dynamic global vegetation model. Global Change Biology, 9, 161 - 185 .

Smith TM ( 1997 ). Examining the consequences of classifying species into functional types: a simulation model analysis. In: Smith TM, Shugart HH, Woodward FI eds. Plant Functional Types: Their Relevance to Ecosystem Properties and Global Change. Cambridge University Press, Cambridge, 271 - 288.

Steffen WL, Walker BH, Ingram JSI, Koch GW (1992). Global Change and Terrestrial Ecosystems: the Operational Plan. IGBP and ICSU, Stockholm.

Tang HP(1999) . Distribution of $\mathrm{C}_{4}$ plants along the Northeast China transect and its correlation to the environmental factors. Chinese Science Bulletin, 44, 1316-1320.
Tranquillini W (1964). The physiology of plant at high altitudes. Annual Review of Plant Physiology, 15, 345 - 362 .

van Minnen JG, Fischer G, Stolbovoi V(1996) . Land-Cover Classification for Modeling Natural Land Cover Within the IIASA Project. WP-96-026 IIASA, Australia.

Woodward FI (1987). Climate and Plant Distribution. Cambridge University Press, Cambridge, $62-116$.

Woodward FI, Kelly CK(1997). Plant functional types: towards a definition by environmental constraints. In: Smith TM, Shugart HH, Woodward FI eds. Plant Functional Types: Their Relevance to Ecosystem Properties and Global Change. Cambridge University Press, Cambridge, 47 - 65.

Woodward FI, McKee IF(1991). Vegetation and climate. Environment International, 17, $535-546$.

Wu ZY (吴征镒) (1980). Vegetation of China (中国植被). Science Press, Beijing. (in Chinese)

Xu WD(徐文铎) (1983). The relation between distribution of edificatory and companion in zonal vegetation and water-temperature condition in Northeast China. Acta Botanica Sinica (植物生态学 报), 25, 264 - 273. (in Chinese with English abstract)

Yan XD(延晓东), Zhao SD(赵士洞) (1996). A model for growth and succession of forest in Changbai Mountain. Acta Ecologica Sinica (生态学报), 14 (Suppl. B), 12 - 21. (in Chinese with English abstract)

Yang ZY (杨正宇), Zhou GS (周广胜), Yang DA (杨奠安) (2003) . Comparison of simulated vegetation distribution in China produced by four popular climate-vegetation classification models. Acta Phytoecologica Sinica (植物生态学报), 27, 587 - 593 . (in Chinese with English abstract)

Zhang XS(张新时) (1993). A vegetation-climate classification system for global change studies in China. Quaternary Science (第四 纪研究), 2, 157 - 169. (in Chinese with English abstract)

Zhao MS(赵茂盛), Neilson RP, Yan XD(延晓东), Dong WJ(董 文杰) (2002). Modelling the vegetation of China under changing climate. Acta Geographica Sinica (地理学报), 57, 28-38. (in Chinese with English abstract)

Zhou GS(周广胜), Zhang XS(张新时) (1996). Study on climatevegetation for global change in China. Acta Botanica Sinica (植 物学报), 38, 8-17. (in Chinese with English abstract) 